\title{
A snake bite case: The value of timely diagnosis and treatment
}

\author{
Shimaa M Motawei* \\ Department of Forensic Medicine \& Clinical Toxicology, Faculty of Medicine, Mansoura University, Egypt
}

\begin{abstract}
Introduction: Venomous snake bites can produce different symptoms. Missing a diagnosis of a toxic snake bite by a medical practitioner will lead to a delay in the specific antivenin administration, hence an unfavorable outcome.

Case presentation: A 29 years old housewife came to the Emergency Department of the Mansoura University Hospital complaining of a swelling in her right arm after an exposure to an unknown bite at her house yard. Initial examination revealed a fully conscious patient with stable vital signs and arterial blood gases. Local examination of the patient's right arm showed edema, redness, hotness, swelling, tenderness and two insertion sites in her right arm with dark tissues around. Diagnosis of a vasculo-toxic snake bite was made, and snake antivenin was promptly administered in the intensive care unit (ICU). Immediate management of any complication was done, e.g. the shock, the impaired kidney functions, lungs infection, and the gangrenous area over the bitten limb. The patient survived and was discharged, with a follow up plan of the gangrenous limb with a plastic surgeon, and complete healing of the affected limb occurred without any residual disability or disfigurement.
\end{abstract}

Conclusion: A snake bite should be suspected in patients presented with a history of bite and a local swelling with local signs of inflammation, even if the biting animal has not been seen. General examination and careful monitoring is important for assessment of patients and consulting different specialties according to the clinical picture of the patient is necessary to reach a favorable outcome.

\begin{abstract}
Abbreviations: PM: post meridiem (in Latin: which means after 12 noon); ED: Emergency Department; /min: per minute; BP: Blood pressure; mmHg: millimeter mercury; RRREC: Regular Reactive Rounded Equal Central; ABG: Arterial blood gases; RBG: Random blood glucose; $\mathrm{CBC}$ : Complete blood counting; $\mathrm{pH}$ : power of hydrogen; $\mathrm{PCO}_{2}$ : Carbon monoxide tension; $\mathrm{PO}_{2}$ : Oxygen tension; $\mathrm{HCO}_{3}$ : Bicarbonate: ALT: Alanine transaminase; IU/L: International Unit per liter; g/dL: gram per deciliter; WBC: White blood cells; /cc: per cubic centimeter; h: hour; US: Ultrasound; IVI: Intravenous infusion; ${ }^{\circ} \mathrm{C}$ : degree centigrade; ${ }^{\circ} \mathrm{F}$ : degree Fahrenheit; $\mathrm{cm}$ : centimeters; DVT: Deep vein thrombosis; Hb: Haemoglobin; ICU: Intensive care unit; INR: International normalized ratio; $\mathrm{mg} / \mathrm{dL}$ : milligram per deciliter.
\end{abstract}

\section{Introduction}

Snakes are elongated, legless, meat-eater reptiles that live on the land, in the sea, in forests, lakes, and in deserts. Most snakes are nonvenomous. Pit vipers and coral snakes can inject venom through fangs from modified salivary glands. Most snakes are non-poisonous, and most bites are non-venomous. Snakes are cold-blooded vertebrates covered with overlapping scales. Thus, they are unable to increase their body temperature and stay active when it is cold outside. They are most active at $25-32^{\circ} \mathrm{C}\left(77-90^{\circ} \mathrm{F}\right)[1]$.

Exposure to snake bites is not a public health problem. Very few deaths occur per year from snakebites in the United States [2].

Snake bite injuries range from simple puncture wounds to lifethreatening illness and death. Venomous snake can produce no symptoms which means a non-toxic bite or can produce symptoms of varying severity either immediately or after a long time interval that may reach up to $36 \mathrm{hr}$ after exposure. The manifestations can be misleading. A victim can have no initial significant symptoms, and then suddenly develop breathing difficulty and go into shock [3].

Toxic snake venoms can be vasculo-toxic, neurotoxic or myotxic, according to the most affected body system. The vasculo-toxic bite (mostly by Viperidae family of snakes) causes manifestations ranging from local pain and swelling at the site of bite, to coagulopathy and cardiac arrest. Neurotoxic snakes (e.g. cobra) produce descending cranial nerve paralysis manifested by of ptosis, dysphonia, dysphagia, dysarthria, difficult breathing up to respiratory failure and death. The myotoxic snakes (mostly the Hydrophadae) produce tissue damage, muscles swelling and pain, muscles destruction and myoglobinuria leading finally to renal failure [4].

Diagnosis of a snake bite case depends upon history, examination, and simple laboratory investigations including arterial blood gases $(\mathrm{ABG})$ and electrolytes, complete blood counting (CBC), coagulation studies (prothrombin time, fibrin degradation products, fibrinogen), creatinine phosphokinase level (CPK) and urine analysis for the presence of blood and/or myoglobin in urine [5].

${ }^{\star}$ Correspondence to: Shimaa M. Motawei, Department of Forensic Medicine \& Clinical Toxicology, Faculty of Medicine, Mansoura University, El-Gomhoria street- Mansoura City, Egypt, Tel: +2/01000371165; E-mail: Sh-mm@mans.edu.eg

Key words: snake bite, suspicion, diagnosis, treatment, complications, favorable outcome

Received: November 18, 2019; Accepted: November 26, 2019; Published: November 29, 2019 
Sometimes the diagnosis may be difficult if the patient did not give a frank history of exposure to a snake bite, however, the site of the bite should be examined for puncture wounds of fangs, and for local signs of inflammation, redness and/or swelling, in addition to the general examination of the patient's body systems functions [6].

The treatment of toxic snake bites depends upon reassurance, supportive measures, and the definitive treatment of toxic bites by the snake antivenin [7].

In this report, a case of a toxic snake bite is presented. The case was denying an exposure to a snake and would have got her limb lost because of gangrene if was not properly diagnosed and timely treated.

\section{Case presentation}

A female patient, 29 years old housewife, from Samanoud, Gharbia Governorate, Egypt, married and has 3 offspring; the youngest is 5 years old, came to the Emergency Department of the Mansoura University Hospital, on Tuesday; October 16, 2018 at 9:00 PM, complaining of pain, redness and swelling of her right arm after exposure to an unknown bite at her house yard nearly $20 \mathrm{hrs}$ before presenting to the ED.

She said she did not receive any treatment or sought medical advice for this bite before coming to our ED.

On examination, the patient was fully conscious; Reed's scale O, pulse $85 / \mathrm{min}$. regular and full, BP $110 / 70 \mathrm{mmHg}$, eye pupils RRREC and the chest was free on auscultation.

Local examination of her right arm showed edema, redness, hotness, swelling, tenderness and two insertion sites with dark tissues around; denoting necrotic tissues and these two sites are mostly the insertion sites of a biting animal, mostly the fangs of a vasculo-toxic snake (Figure 1).

Cleaning and debridement of the bite site was done, and blood samples were withdrawn for bedside tests of ABG and RBG. The patient was admitted to the ICU with fluid therapy, symptomatic support, continuous monitoring and plastic and vascular surgery consultations were done to manage the swelling and tissue necrosis in the affected limb. Snake antivenin was recommended and promptly administered alongside the symptomatic care and monitoring. Anti-edema and antacids were given. Ten vials of the polyvalent snake antivenin were given by intravenous infusion with a short-acting corticosteroid and an antihistaminic infusion in another intravenous line. Doppler US was done that revealed no superficial thrombophlebitis nor DVT. The Vascular Surgery specialist reported that the right arm's arteries were patent and pulsatile. The right arm's veins were patent and totally compressible. Subcutaneous and interstitial edema was detected in a swelling in the right arm.
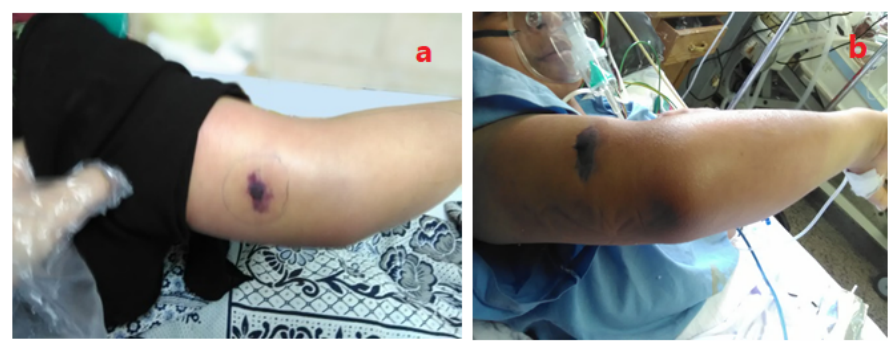

Figure 1. Dark red area with tissue necrosis in a bitten limb of the patient, mostly a vasculotoxic snake bite showing local signs of inflammation and necrosis of the tissues. (a) On presentation to the ED, (b) 24 hours after admission to the ICU
The patient's $\mathrm{ABG}$ on presentation showed $\mathrm{pH} 7.44, \mathrm{PCO}_{2} 33, \mathrm{PO}_{2}$ $103, \mathrm{HCO}_{3} 24$. Liver functions tests showed serum ALT $18 \mathrm{IU}$, serum Albumin $3.2 \mathrm{~g} / \mathrm{dL}$, serum bilirubin $0.29 \mathrm{mg} / \mathrm{dL}$. Random blood glucose was $122 \mathrm{mg} / \mathrm{dL}$. CBC showed leukocytosis WBCs count $20000 / \mathrm{cc}, \mathrm{Hb}$ $11.2 \mathrm{~g} / \mathrm{dl}$, platelets $395000 / \mathrm{cc}$, INR 1.25 .

Full routine laboratory testing was done. Serum creatinine was 5 $\mathrm{mg} / \mathrm{dL}$, urine analysis showed dark brown urine color, and its amount was $1500 \mathrm{~mL} /$ day, with blood but no myoglobin was found in urine. $\mathrm{O}_{2}$ saturation was $91-94 \%$ without a ventilation aid (e.g. $\mathrm{O}_{2}$ mask).

Chest X-ray showed white shadows of lungs infiltration. Chest consultation informed that there is a lung infection, and they prescribed the appropriate antibiotics for the patient based upon a sputum culture.

The patient showed slight deterioration of consciousness and the blood pressure, despite the treatment and fluid support. The heart rate was 110 beats/min. regular, weak. BP $90 / 60 \mathrm{mmHg}$ and she was drowsy (Reed's scale I). The local site did show more extension of the swelling in the patient's right arm.

Additional fifteen vials of the polyvalent snake antivenin were administered IVI with ready bed-side anti-shock measures (Antihistaminic, adrenaline and corticosteroids) were available upon need.

On the third day; Oct. 18, 2018, the patient regained her full consciousness. Pulse was $80 / \mathrm{min}$., full, regular, BP $120 / 80 \mathrm{mmHg}$, regression of the swelling and pain in the affected right arm.

Serum creatinine dropped to $1.2 \mathrm{mg} / \mathrm{dL}$, urine analysis showed normal colored urine and average volume per day.

Continuous monitoring and follow up with the care of a combined team of toxicologists, plastic and vascular surgeons. The swelling in the right arm decreased in size, edema and redness disappeared, but developed an ulcer at the site; measuring about $2 \mathrm{by} 1 \mathrm{~cm}$ and covered with necrotic tissues.

The patient remained $36 \mathrm{hr}$ fully conscious, with stable vital signs. She was discharged on Oct. 20, 2018, with follow up with the plastic surgery outpatient for the management of the affected arm tissue necrosis.

Her laboratory data on discharge were: $\mathrm{pH} 7.42, \mathrm{PCO}_{2} 34, \mathrm{PO}_{2}$ $107, \mathrm{HCO}_{3} 23.4$; liver functions testing showed serum ALT $22 \mathrm{IU} / \mathrm{L}$, Albumin $3.2 \mathrm{~g} / \mathrm{dL}$; bilirubin $0.37 \mathrm{mg} / \mathrm{dL}$; RBG $150 \mathrm{mg} / \mathrm{dL}$, serum creatinine $0.9 \mathrm{mg} / \mathrm{dL}$.

The plastic surgeon reported healing of the patient's ulcer after six weeks of good follow up in the surgery outpatient clinic.

\section{Discussion}

Snake bites is not a public health problem, making knowledge and attitudes towards this exposure not very clear for many medical practitioners. This results in delay in diagnosis and hence in treatment, leading to complications that may be fatal [7].

Williams, et al. called for a strategy for a globally coordinated response towards snake bite envenoming as a priority neglected tropical disease, so can avoid complications due to the possible lack of the proper diagnosis and treatment of such cases [8].

The vasculo-toxic, neurologic sequelae, muscle destruction and secondary renal failure are the most common complications of snake bites. Despite snake venom toxicity is infrequent, they can cause 
significant local and systemic damage if not diagnosed and properly treated [9].

Few data exist to understand the recovery phase of pit viper envenomation. The reporting of the cases of vasculo-toxic snake bites in different geographical areas would then be beneficial for medical practitioners and scientists [9].

In this case, a female patient from the Delta region in Egypt came to ED with a history of unknown bite in her right arm at her house yard. She did not care to consult for the exposure until a swelling appeared in the arm of her bitten limb nearly 20 hours after the incident. With the duration since exposure (nearly $20 \mathrm{hr}$ ), the unknown type of bite, and her residence locality is not known to be an endemic locality of poisonous snakes in the country, examination will be the key for clinicians to diagnose the case.

When local examination of the patient's bitten limb showed local edema, redness, hotness, swelling, tenderness at the right arm, and two insertion sites with dark tissues around. This denotes necrotic tissues and that these two sites are mostly the insertion sites of a biting animal, mostly the fangs of a vasculo-toxic snake.

Suspicion was important in such a case to begin treatment with the specific anti-snake antivenin, so that it can stop the necrotic changes at the bitten limb that may proceed to gangrene and a limb or a patient loss if not treated, the vasculo-toxic venom may cause cardiac depression, cardiogenic shock, coagulopathy and other complications of vasculotoxicity of snake bites. Gangrene can cause an intractable septic shock and death.

The regression of the manifestations in the described case above, after administration of the antivenin, together with symptomatic care and appropriate consultations, confirms the diagnosis of a vasculotoxic snake bite despite the lack of history of any snake exposure.

The knowledge about this rare tropical disease will become important to save victims of such exposures even if the history is deficient or lacking for a definite animal exposure being nominated as a cause of the complaint.

Esiéné, et al. in Cameroon, reported a case of a severe vasculo-toxic snake envenomation in a female farmer that showed a cardiogenic shock, AKI and gangrene of the entire right upper limb; the bitten limb. With the patient's delay to be rushed to the ED, septic shock supervened that caused the patient to be lost [11].

The authors concluded that the lack of health education, patient's delay to seek the medical care, false public beliefs about toxic exposures including snake bites, and unsupervised traditional medications were behind the poor outcome of their described case [11].

This is similar to the case in this report as she came late to seek the medical care when a dark swelling developed in her bitten limb, but our patient survived despite shock and infection that developed few hours after hospitalization.

Warning from the risks of traditional medications and unsupervised use of herbal preparations goes with Motawei recommendations regarding traditional medicines [12].

Serum creatinine was high in the patient upon admission and the urine was dark brown in color, denoting touching of the kidney secondary to the shock and coagulopathy of the vasculo-toxic snake venom affecting the victim.
These findings go with Dawman, et al. [13], Vikrant, et al. [14], Naqvi [15] and many other authors from different localities [16,17] who found renal failure in victims of snake bites.

The case developed lung infection few hours after admission to the ICU to give the antivenin therapy. This lung infection was timely and properly treated with the joint care of the Pulmonary Medicine specialist after doing all the necessary laboratory, the sputum culture and the radiologic investigations. This goes with Williams, et al. who accepted snake bite victims to be susceptible to hospital infections of many kinds, and should be treated according to a clear protocol.

The hypotension and the impaired consciousness state that developed in the case in the second day after hospitalization and after initiation of IVI antivenin therapy, denoted severe degree of poisoning. Administration of additional fifteen vials of the snake antivenin reversed the symptoms and the patient regained the full consciousness with normal vital signs $36 \mathrm{hr}$ after hospitalization.

The dark-colored right arm swelling and the ulcer that developed over the bitten site, were cared for with the specialized plastic surgeon with the proper investigations done. The US revealing patent vasculature of the arm despite the presence of necrotic tissue around the bitten site denotes that it is only a skin necrosis and there is no compartmental syndrome or necrotizing fasciitis [18].

The further follow up of the patient in the outpatient clinic of the plastic surgery and the patient's adherence to dates of the follow up and the good wound care, resulted in healing of the ulcer, stop of the tissues necrosis, removal of the necrotic tissues, and complete healing of the site without any residual disfigurement.

These findings go with what Esiéné, et al. [11] who described a state of shock, limb gangrene and AKI complicating a case of Viperidae envenomation that was presented late to the ED and died because of the complications.

The successful outcome of the case presented in this report signifies the value of the timely diagnosis of snake bite cases, the importance of the consultations of other specialties for a proper treatment of the existing and possible complications in such cases, the necessity of timely and proper administration of the snake antivenin for the diagnosed cases of toxic snake bites and the importance of the sense of suspicion to diagnose such cases if the history is lacking an exposure to a snake.

\section{Conclusion}

Snake bite is an uncommon tropical disease. Most snakes are non-poisonous. Poisonous snake's exposure accounts for only $10 \%$ of the total snake bites exposures. However, toxic snake bites may result into severe complications that lead to death of the victim or a major disability. This case report denotes the importance of education of the public of the pitfalls to avoid after snake bites exposure, and the necessity of quick seeking the medical care after a bite exposure even if lacking seeing the biting animal. Also, it confirms for clinical practitioners about the value of timely diagnosis and treatment that is a gold standard in Toxicology practice, and it is pivotal in snake bite cases to reach a favorable outcome.

\section{References}

1. Stewart JR, Blackburn DG (2019) A developmental synapomorphy of squamate reptiles. Evol Dev 21: 342-353.

2. Kawai N, Qiu H (2019) Humans detect snakes more accurately and quickly than other animals under natural visual scenes: a flicker paradigm study. Cogn Emot 25: 1-7. 
3. Gutiérrez JM, Calvete JJ, Habib AG, Harrison RA, Williams DJ, et al. (2017) Snakebite envenoming. Nat Rev Dis Primers 3: 17063.

4. Domanski K, Kleinschmidt KC, Greene S, Ruha AM, Berbata V, et al. (2019) Cottonmouth snake bites reported to the Toxic North American snakebite registry 20132017. Clin Toxicol (Phila) 13: 1-5.

5. Fuchs J, Bessire K, Weiler S (2019) A confirmed bite by a beautiful pit viper (Trimeresurus venustus) resulting in local symptoms. Toxicon 163: 44-47.

6. Benjamin JM, Chippaux JP, Jackson K, Ashe S, Tamou-Sambo B, et al. (2019) Differential diagnosis of an unusual snakebite presentation in Benin: Dry bite or envenomation?. J Spec Oper Med 19:18-22.

7. Lavonas EJ, Burnham RI, Schwarz J, Quackenbush E, Lewis B, et al. (2019) Recovery from copperhead snake envenomation: Role of age, sex, bite location, severity, and treatment. J Med Toxicol.

8. Williams DJ, Faiz MA, Abela-Ridder B, Ainsworth S, Bulfone TC, et al. (2019) Strategy for a globally coordinated response to a priority neglected tropical disease: Snakebite envenoming. PLoS Negl Trop Dis 13: e0007059.

9. The Lancet (2017) Snake-bite envenoming: a priority neglected tropical disease. Lancet 390: 2

10. Ruha AM, Kleinschmidt KC, Greene S, Spyres MB, Brent J, et al. (2017) The epidemiology, clinical course, and management of snakebites in the North American Snakebite Registry. J Med Toxicol 13: 309-320.
11. Esiéné A, Etoundi PO, Tochie JN, Metogo AJM, Minkande JZ (2019) Severe Viperidae envenomation complicated by a state of shock, acute kidney injury, and gangrene presenting late at the emergency department: a case report. BMC Emerg Med 19: 26.

12. Motawei SM (2014) Hazards of herbal prescriptions: A case report and a review. American Journal of Medical Case Reports 2: 214-217.

13. Dawman L, Sekar A, Varma TH, Nada R, Tiewsoh K (2019) Snake bite-induced renal medullary angitiis in a child: A case report. Saudi J Kidney Dis Transpl 30: 231-234.

14. Vikrant S, Jaryal A, Parashar A (2017) Clinico-pathological spectrum of snake biteinduced acute kidney injury from India. World J Nephrol 6: 150-161.

15. Naqvi R (2016) Snake-bite-induced acute kidney injury. J Coll Physicians Surg Pak 26: $517-520$.

16. Li W, Chen F, Wu S (2016) The related risk factors analysis of snake-bite induced acute kidney injury. 2016. Med Sci Monit 22: 2335-2339.

17. Ratnayake I, Mohamed F, Buckley NA, Gawarammana IB, Dissanayake DM, et al (2019) Early identification of acute kidney injury in Russell's viper (Daboia russelii) envenoming using renal biomarkers. PLoS Negl Trop Dis 13: e0007486.

18. Binu JA, Mishra AK, Gunasekaran K, Iyadurai R (2019) Cardiovascular manifestation and patient outcomes following snake envenomation: a pilot study. Trop Doct 49: 1013.

Copyright: (C2019 Motawei SM. This is an open-access article distributed under the terms of the Creative Commons Attribution License, which permits unrestricted use, distribution, and reproduction in any medium, provided the original author and source are credited. 